This item was submitted to Loughborough's Research Repository by the author.

Items in Figshare are protected by copyright, with all rights reserved, unless otherwise indicated.

\title{
A motion analysis marker-based method of determining centre of pressure during two-legged hopping
}

PLEASE CITE THE PUBLISHED VERSION

http://dx.doi.org/10.1016/j.jbiomech.2014.04.008

\section{PUBLISHER}

(C) Elsevier

\section{VERSION}

AM (Accepted Manuscript)

\section{PUBLISHER STATEMENT}

This work is made available according to the conditions of the Creative Commons Attribution-NonCommercialNoDerivatives 4.0 International (CC BY-NC-ND 4.0) licence. Full details of this licence are available at: https://creativecommons.org/licenses/by-nc-nd/4.0/

\section{LICENCE}

CC BY-NC-ND 4.0

\section{REPOSITORY RECORD}

Furlong, Laura-Anne, and Andrew J. Harrison. 2019. "A Motion Analysis Marker-based Method of Determining Centre of Pressure During Two-legged Hopping”. figshare. https://hdl.handle.net/2134/25220. 
A motion analysis marker-based method of determining centre of pressure during twolegged hopping

Laura-Anne M Furlong and Andrew J Harrison

Biomechanics Research Unit, Department of Physical Education and Sport Sciences, University of Limerick, Castletroy, Limerick, Ireland.

Corresponding author telephone: +35361234715

Corresponding author email: laura-anne.furlong@ul.ie 


\section{Abstract:}

The fixed position of force plates has led researchers to pursue alternative methods of determining centre of pressure $(\mathrm{CoP})$ location. To date, errors reported using alternative methods to the force plate during dynamic tasks have been high. The aim of this study was to investigate the accuracy of a motion analysis marker-based system to determine CoP during a two-legged hopping task. Five markers were attached to the left and right feet of eight healthy adults ( 5 females, 3 males, age: $25.0 \pm 2.8$ years, height: $1.75 \pm 0.07$ $\mathrm{m}$, mass: $71.3 \pm 11.3 \mathrm{~kg}$ ). Multivariate forward stepwise and forced entry linear regression was used with data from five participants to determine CoP position during quiet standing and hopping task at various frequencies. Maximum standard error of the estimate of CoP position was $12 \mathrm{~mm}$ in the anteroposterior direction and $8 \mathrm{~mm}$ in the mediolateral. Cross-validation was performed using the remaining three participants. Maximum root mean square difference between the force plate and marker method was 14 $\mathrm{mm}$ for mediolateral $\mathrm{CoP}$ and $20 \mathrm{~mm}$ for anteroposterior CoP during $1.5 \mathrm{~Hz}$ hopping. Differences reduced to a maximum of $7 \mathrm{~mm}$ (mediolateral) and $14 \mathrm{~mm}$ (anteroposterior) for the other frequencies. The smallest difference in calculated sagittal plane ankle moment and timing of maximum moment was during $3.0 \mathrm{~Hz}$ hopping, and largest at $1.5 \mathrm{~Hz}$. Results indicate the marker-based method of determining CoP may be a suitable alternative to a force plate to determine CoP position during a two-legged hopping task at frequencies greater than $1.5 \mathrm{~Hz}$.

Keywords: kinematics, inverse dynamics, regression, force plate, hopping frequency 


\section{Introduction}

Centre of pressure (CoP) refers to the point of application of the ground reaction force which is normally acquired using a force plate (FP). CoP position, position change and magnitude of area within which it moves are of interest to researchers during both standing and dynamic tasks such as hopping, walking and running (Han et al., 1999; Hertel et al., 2006; Lafond et al., 2004). It is also used as an input for inverse dynamics calculations of joint torques (McCaw and Devita, 1995). The fixed location of most FPs has led researchers to attempt to find more mobile alternatives to determine CoP position such as in-shoe devices (Chesnin et al., 2000; Forner Cordero et al., 2004; Fradet et al., 2009). However, due to large reported differences between the FP and these methods, the FP still remains the most commonly used method of obtaining CoP.

Root mean square difference (RMSD) between CoP determined using a FP and in-shoe measurement systems has previously been reported to be between $15 \mathrm{~mm}$ during quiet standing and $41 \mathrm{~mm}$ during walking (Chesnin et al., 2000; Fradet et al., 2009). Differences are most likely due to insole movement, incorrect transformation of co-ordinates from local to global systems or temporal synchronisation error (O'Connor et al., 1995). Pillet et al. (2010) used a motion analysis anthropometric-based model to determine CoP in static and self-selected speed walking tasks. RMSD was between $14.2 \pm 5.2$ and $17.6 \pm 5.7 \mathrm{~mm}$ in the mediolateral (ML) direction and $33.0 \pm 4.2 \mathrm{~mm}$ and $43.4 \pm 5.7 \mathrm{~mm}$ in the anteroposterior (AP) direction. Shifts in $\mathrm{CoP}$ of these magnitudes have been shown to significantly affect sagittal plane joint torque calculation by 19.5\% to $48.2 \%$ (Kim et al., 2007; McCaw and Devita, 1995).

Motion analysis is often used to determine kinematics during dynamic tasks. Use of a motion analysis marker-based method of determining $\mathrm{CoP}$ could allow researchers and clinicians to measure CoP in a variety of locations. The aim of this study was to investigate the accuracy of a motion analysis marker-based method to determine CoP by comparing values obtained with those obtained from a FP. Ideally this would use as few markers as possible and return similar values to the FP. 


\section{Methods}

\subsection{Participants and participant preparation}

Following university ethics committee approval, eight healthy, active adults ( 5 females, 3 males, age: 25.0 \pm 2.83 years, height: $1.75 \pm 0.07 \mathrm{~m}$, mass: $71.3 \pm 11.3 \mathrm{~kg}$ ) consented to participate in this study. Retro-reflective markers $(9.5 \mathrm{~mm})$ were attached to the superior first and third metatarsophalangeal joints (1MTP and 3MTP), lateral $5^{\text {th }}$ metatarsophalangeal joint (5MTP), at half the length of the foot in line with 3MTP (midfoot; MF) and on the superior foot at the point where it joined the leg (groove; GR). Familiarisation consisted of at least ten hops at each test frequency $(1.5 \mathrm{~Hz}, 2.2 \mathrm{~Hz}, 3.0 \mathrm{~Hz}$ and a selfselected frequency) until participants were striking the FP in time with the digital metronome (TempoPerfect Metronome Software v2.02, NCH Software, Canberra, Australia).

\subsection{Data acquisition}

All trials were captured using a six camera 3D motion analysis system $(300 \mathrm{~Hz}$, MAC Eagle, Motion Analysis Corporation Inc., Santa Rosa, CA., USA) and two AMTI force plates (300 Hz, AMTI OR6-7, Watertown, MA., USA). This sample rate was considered appropriate as the purpose of data collection was to obtain simultaneous marker kinematics and $\mathrm{CoP}$ data rather than investigate changes in $\mathrm{CoP}$ position or force with time. Testing consisted of two two-legged hopping trials of 30 seconds duration at each test frequency with one foot on each FP and during quiet standing. The two-legged hopping movement was similar to that performed by Farley and Morgenroth (1999) and Hobara et al. (2010), where the two feet were positioned hip width apart and both legs jumped simultaneously in place. FP X and $\mathrm{Y}$ axes were aligned to the ML and AP directions respectively. The FP was re-zeroed between every trial to minimise drift, however some trials required re-zeroing in post-processing to produce a zero force value when nothing was on the plate.

\subsection{Data processing}

Markers were filtered using a fourth order, zero lag, low-pass Butterworth filter in the motion analysis software with cut-offs of $14 \mathrm{~Hz}$ (1MTP, 3MTP), $13 \mathrm{~Hz}$ (5MTP) and $17 \mathrm{~Hz}$ (MF, GR) based on residual analyses (Winter, 2005). CoP data calculated using vertical forces of less than $100 \mathrm{~N}$ and occurring in the 
outer $10 \mathrm{~cm}$ edges of the FP were removed from analysis due to previously reported inaccuracies in $\mathrm{CoP}$ measurement at low force levels and the outer edges of the FP (Bobbert and Schamhardt, 1990; Middleton et al., 1999). Only ML CoP data occurring within the width of the foot were included in analysis due to the improbability of the CoP being outside the foot when the foot was in contact with the plate at high forces.

\subsection{Error checking}

A calibrated mass $(9.815 \mathrm{~kg})$ was placed on the FP close to the centre of the plate, then to the right, left, behind and front of this position for $30 \mathrm{~s}$ each to estimate $\mathrm{CoP}$ deviation when an inanimate object was placed on it. The influence of zeroing in post-processing was estimated by comparing the same trial twice with the trial zeroed at different points.

\subsection{Statistical analysis}

All statistical analysis was completed using SPSS Statistics 20 (IBM, Armonk, NY, USA). CoP data from five participants were used for initial equation derivation. Multivariate forward stepwise linear regression $\left(p_{\text {in }}=0.05, p_{\text {out }}=0.10\right)$ was used to derive frequency-specific equations for predicting CoP position from all the marker kinematics in the $\mathrm{X}, \mathrm{Y}$ and $\mathrm{Z}$ axes. The most important markers to predict $\mathrm{CoP}$ in $\mathrm{ML}$ and AP directions were identified with consideration to prevalence in equations and practicalities of marker location. Co-ordinate data from all three axes for these markers were then entered into multivariate forced entry linear regression (table 4). All input data was marker kinematics in metres. To clarify presentation, standard error of the estimate and cross-validation results are presented in millimetres.

\subsection{Cross-validation and establishment of difference between methods}

Adjusted $\mathrm{r}^{2}$ was calculated during forced entry regression to provide an estimate of explained variance in the population. Cross-validation was completed using data from the remaining three participants to determine how well the model predicted CoP in similar adults from outside the sample. RMSD between CoP measured using the FP and the marker-based method was calculated for these participants. 95\% confidence interval of the difference between the two methods for all eight participants was calculated to provide an estimate of the predictive ability of the equations. Pearson's $r$ was calculated to investigate the 
strength of the linear relationship between the two methods with the correlation considered very large when between.7 and.9, and 'nearly perfect' when greater than .9 (Hopkins, 2006).

\subsection{Influence of use of marker-based method on sagittal plane ankle joint moment}

To investigate the effect of use of this method on sagittal plane ankle moment when horizontal and vertical forces were known, additional markers were placed on the lateral malleoli of six of the eight participants and filtered at $14 \mathrm{~Hz}$. Three participants were chosen at random for analysis at each frequency. Moments were calculated using both FP CoP and marker-based CoP with the equations of Winter (2005) and the segment inertia model of Dempster (1955). RMSD of calculated moments across the entire impact and absolute difference between calculated maximum moment and timing of maximum moment were calculated for each impact using a custom-written Visual Basic macro (Microsoft Inc., WA., USA).

\section{Results}

The number of data points included in analysis are shown in tables 1 and 2. During the static plate trial, CoP location was shown to deviate by between 0.4 and $0.7 \mathrm{~mm}$ in both $\mathrm{X}$ and $\mathrm{Y}$ axes, dependent on the position of the mass on the plate. Post-zeroing the plate affected CoP by 2 to $3 \mathrm{~mm}$ in the $\mathrm{X}$ axis and 1 $\mathrm{mm}$ in the $\mathrm{Y}$.

Use of a two marker model explained high levels of variance (91.4\% to $99.9 \%)$ and resulted in small SEE (1 to $14 \mathrm{~mm}$, table 3). A full model improved predictive ability slightly with $92.8 \%$ to $99.9 \%$ explained variance, and smaller SEE (1 to $11 \mathrm{~mm}$ ). The prevalence of the 1MTP and MF markers and necessity of the 5MTP marker in inverse dynamics analysis formed the basis of selection for markers in the forced entry regression equations.

Forced entry regression resulted in similar $r^{2}$ to that of the full 5 marker set in the forward stepwise regression (table 4). SEE was 1 to $8 \mathrm{~mm}$ (ML) and 3 to $12 \mathrm{~mm}$ (AP). 95\% confidence intervals (CI) in the ML direction ranged from $4 \mathrm{~mm}$ in quiet standing up to $18 \mathrm{~mm}$ during $1.5 \mathrm{~Hz}$ hopping. In the AP, values ranged from $16 \mathrm{~mm}$ in $3 \mathrm{~Hz}$ hopping to $28 \mathrm{~mm}$ in $1.5 \mathrm{~Hz}$ hopping. Almost perfect relationships $(\mathrm{r} \geq .95)$ 
were observed between the two methods for all equations, except for ML CoP of the right foot during $1.5 \mathrm{~Hz}$ hopping which was very strong (.87).

The effect of use of the regression method on sagittal plane ankle moment calculation when force is known is shown in table 5. Similar average maximum moments were observed across all frequencies of between 135 and 142 N.m. While similar RMSD and absolute difference in moment was observed across frequencies, large differences in the timing of the maximum moment were observed during $1.5 \mathrm{~Hz}$ hopping.

\section{Discussion}

The aim of this study was to investigate the accuracy of a motion analysis marker-based method to determine CoP, by comparing values obtained with those obtained from a FP. For standing and all frequencies, CoP predictive ability was greater in the ML direction than AP. FP accuracy is greater in the short $(\mathrm{X})$ axis than the long $(\mathrm{Y})$ axis due to the smaller distance between the transducers used to determine the forces and position (Bobbert and Schamhardt, 1990; Middleton et al., 1999). CoP movement in the ML direction is also smaller than the AP direction during unidirectional, single plane hopping therefore the predictive equation only needs to operate within a small range.

Use of a reduced number of markers resulted in similar SEE to that of a full five marker set (table 4). Considering the accuracy of this FP for CoP is 1 to $1.5 \mathrm{~mm}$ in static loading, plate noise is 0.4 to $0.7 \mathrm{~mm}$, re-zeroing in post-processing may affect CoP by a further 1 to $3 \mathrm{~mm}$ and previously reported inaccuracies of measurement of CoP using the FP during dynamic tasks (Bobbert and Schamhardt, 1990), it appears the motion analysis system performed well in determining CoP. SEE results suggest good predictive abilities of the regression equations with maximum ML SEE of $8 \mathrm{~mm}$ and AP SEE of $12 \mathrm{~mm}$ for all frequencies apart from 1.5 Hz. RMSD for the cross-validated participants for most conditions were similar to SEE. Cross-validated RMSD was lower than those previously reported. Pillet et al. (2010) reported RMSD of approximately $18 \mathrm{~mm}(\mathrm{ML})$ and $43 \mathrm{~mm}$ (AP) during walking. This method may be more accurate because the markers used are closer to the CoP than the full body marker sets used in their study. Removal of spatial and temporal error may explain the lower differences in CoP position and timing of maximum moment reported here compared to Chesnin et al. (2000), Fradet et al. (2009) and 
Chumanov et al. (2010). Average difference in CoP position was low with correspondingly low 95\% CI, and very large linear relationships between CoP using both methods were observed.

Cross-validated RMSD in $1.5 \mathrm{~Hz}$ hopping was $14 \mathrm{~mm}$ (ML) and $20 \mathrm{~mm}$ (AP). There were differences between SEE and cross-validated RMSD of 1 to $1.1 \mathrm{~mm}$ (ML) and $8 \mathrm{~mm}$ (AP). The 95\% CI for difference between methods was very large $(28 \mathrm{~mm})$, and the timing of maximum moment using the two methods was excessively large with an average absolute difference of $36 \pm 83 \mathrm{~ms}$. This suggests the regression method is inappropriate for $1.5 \mathrm{~Hz}$ hopping, probably due to the increased variability and range of motion of the ankle at this particular frequency with corresponding decreased joint stiffness (Hobara et al., 2011), excessive foot spread during impact and presence of double-peak vertical ground reaction forces.

Results show a motion analysis marker-based method using markers at the 1MTP, 5MTP and mid-foot position can determine CoP position during quiet standing and two-legged hopping at frequencies greater than $1.5 \mathrm{~Hz}$ with reasonable accuracy. These results are promising in terms of their potential application as an alternative method of determining CoP without a FP. However, the results of this study are limited to quiet standing and two-legged hopping in healthy adults. Further work is required to investigate the accuracy of the method in walking and running, or with clinical populations.

\section{Conflict of interest}

There is no potential conflict of interest influencing this work.

\section{Acknowledgements}

The authors wish to thank the Irish Research Council for providing funding to support this work under the Embark Initiative. These sponsors had no involvement in the study design, data collection, analysis or interpretation, writing of the manuscript or in the decision to submit the manuscript for publication. 


\section{References}

Bobbert, M.F., Schamhardt, H.C., 1990. Accuracy of determining the point of force application with piezoelectric force plates. Journal of Biomechanics 23, 705-710.

Chesnin, K.J., Selby-Silverstein, L., Besser, M.P., 2000. Comparison of an in-shoe pressure measurement device to a force plate: concurrent validity of center of pressure measurements. Gait and Posture 12, 128133.

Chumanov, E., Remy, C., Thelen, D., 2010. Computational techniques for using insole pressure sensors to analyse three-dimensional joint kinetics. Computer Methods in Biomechanics and Biomedical Engineering 13, 505-514.

Dempster, W.T., 1955. Space requirements of the seated operator. Wright-Patterson Air Force Base, Ohio.

Farley, C., T., Morgenroth, D., C. , 1999. Leg stiffness primarily depends on ankle stiffness during human hopping. Journal of Biomechanics 32, 267-273.

Forner Cordero, A., Koopman, H.J.F.M., van der Helm, F.C.T., 2004. Use of pressure insoles to calculate the complete ground reaction forces. Journal of Biomechanics 37, 1427-1432.

Fradet, L., Siegel, J., Dahl, M., Alimusaj, M., Wolf, S.I., 2009. Spatial synchronization of an insole pressure distribution system with a 3D motion analysis system for center of pressure measurements. Medical and Biological Engineering and Computing 47, 85-92.

Han, T., Paik, N., Im, M., 1999. Quantification of the path of the center of pressure (COP) using an Fscan in-shoe transducer. Gait and Posture 10, 248-254.

Hertel, J., Olmsted-Kramer, L., Challis, J., 2006. Time-to-boundary measures of postural control during single leg quiet standing. Journal of Applied Biomechanics 22, 67-73.

Hobara, H., Inoue, K., Muraoka, T., Omuro, K., Sakamoto, M., Kanosue, K., 2010. Leg stiffness adjustment for a range of hopping frequencies in humans. Journal of Biomechanics 43, 506-511.

Hobara, H., Inoue, K., Omuro, K., Muraoka, T., Kanosue, K., 2011. Determinant of leg stiffness during hopping is frequency-dependent. European Journal of Applied Physiology 111, 2195-2201.

Hopkins, W., 2006. A New View of Statistics: A Scale of Magnitudes for Effect Sizes, http://www.sportsci.org/resource/stats/effectmag.html.

Kim, H.-Y., Sakurai, S., Ahn, J.-H., 2007. Errors in the measurement of centre of pressue (CoP) computed with force plate affect on 3D lower limb joint moment during gait. International Journal of Sport and Health Science 5, 71-82.

Lafond, D., Corriveau, H., Hébert, R., Prince, F., 2004. Intrasession reliability of center of pressure measures of postural steadiness in healthy elderly people. Archives of Physical Medicine and Rehabilitation 85, 896-901.

McCaw, S.T., Devita, P., 1995. Errors in alignment of center of pressure and foot coordinates affect predicted lower-extremity torques. Journal of Biomechanics 28, 985-988.

Middleton, J., Sinclair, P., Patton, R., 1999. Accuracy of centre of pressure measurement using a piezoelectric force platform. Clinical Biomechanics 14, 357-360.

O'Connor, B.J., Yack, H.J., White, S.C., 1995. Reducing errors in kinetic calculations - improved synchronization of video and ground reaction force records. Journal of Applied Biomechanics 11, 216223.

Pillet, H., Bonnet, X., Lavaste, F., Skalli, W., 2010. Evaluation of force plate-less estimation of the trajectory of the centre of pressure during gait. Comparison of two anthropometric models. Gait and Posture 31, 147-152.

Winter, D.A., 2005. Kinematics, Chapter 2, Biomechanics and Motor Control of Human Movement, 3rd ed. John Wiley and Sons Inc., New York. 
Table 1. Numbers of data points used in multivariate forward stepwise and forced entry regression

Number of data points used

Frequency (Hz) Mediolateral left $\quad$ Mediolateral right $\quad$ Anteroposterior

Quiet standing

5355

13277

18632

1.5

4804

10452

15256

2.2

5337

4682

10019

3.0

4698

9495

14193

Self-selected

6382

6586

12968 
Number of data points used

\begin{tabular}{cccc} 
Frequency $(\mathrm{Hz})$ & Mediolateral left & Mediolateral right & Anteroposterior \\
\hline Quiet standing & 4691 & 2144 & 6835 \\
1.5 & 1654 & 3340 & 4994 \\
2.2 & 1014 & 2298 & 3312 \\
3.0 & 3235 & 3787 & 7022 \\
Self-selected & 11778 & 3598 & 15376 \\
\hline
\end{tabular}


Table 3. Initial multivariate forward stepwise regression analysis to identify main predictors of centre of pressure position in mediolateral and anteroposterior directions.

\begin{tabular}{|c|c|c|c|}
\hline Frequency and direction & Predictors used & $\mathrm{R}^{2}$ & $\mathrm{SEE}(\mathrm{mm})$ \\
\hline \multirow{3}{*}{ Quiet standing (left) } & $\mathrm{MF}_{\mathrm{X}}, \mathrm{GR}_{\mathrm{Y}}$ & .999 & 1 \\
\hline & $5 \mathrm{MTP}_{\mathrm{X}}, \mathrm{MF}_{\mathrm{X}, \mathrm{Z}}, \mathrm{GR}_{\mathrm{X}}$ & .999 & 1 \\
\hline & Full model & .999 & 1 \\
\hline \multirow{3}{*}{ Quiet standing (right) } & $\mathrm{MF}_{\mathrm{X}, \mathrm{Z}}, \mathrm{GR}_{\mathrm{Z}}$ & .997 & 1 \\
\hline & $3 \mathrm{MTP}_{\mathrm{Z}}, \mathrm{MF}_{\mathrm{X}, \mathrm{Z}}, \mathrm{GR}_{\mathrm{Z}}$ & .997 & 1 \\
\hline & Full model & .998 & 1 \\
\hline \multirow{3}{*}{$\begin{array}{l}\text { Quiet standing } \\
\text { (anteroposterior) }\end{array}$} & $3 \mathrm{MTP}_{\mathrm{Z}}, 5 \mathrm{MTP}_{\mathrm{Y}}$ & .937 & 7 \\
\hline & $3 \mathrm{MTP}_{\mathrm{Z}}, 5 \mathrm{MTP}_{\mathrm{Y}, \mathrm{Z}}, \mathrm{MF}_{\mathrm{Y}, \mathrm{Z}}$ & .959 & 6 \\
\hline & Full model & .989 & 3 \\
\hline \multirow{3}{*}{$1.5 \mathrm{~Hz}$ mediolateral (left) } & $1 \mathrm{MTP}_{\mathrm{x}}$ and $\mathrm{GR}_{\mathrm{x}}$ & .987 & 5 \\
\hline & $1 \mathrm{MTP}_{\mathrm{x}, \mathrm{z},} 5 \mathrm{MTP}_{\mathrm{z}}$ and $\mathrm{GR}_{\mathrm{x}}$ & .993 & 3 \\
\hline & Full model & .994 & 3 \\
\hline \multirow{3}{*}{$1.5 \mathrm{~Hz}$ mediolateral (right) } & $1 \mathrm{MTP}_{\mathrm{x}}$ and $5 \mathrm{MTP}_{\mathrm{x}}$ & .960 & 6 \\
\hline & $1 \mathrm{MTP}_{\mathrm{x}}, 5 \mathrm{MTP}_{\mathrm{x}}$ and $\mathrm{MF}_{\mathrm{z}}$ & .965 & 6 \\
\hline & Full model & .985 & 4 \\
\hline
\end{tabular}




\begin{tabular}{|c|c|c|c|}
\hline \multirow{3}{*}{$1.5 \mathrm{~Hz}$ (anteroposterior) } & $\mathrm{MF}_{\mathrm{Y}, \mathrm{Z}}, 1 \mathrm{MTP}$ & .959 & 14 \\
\hline & $\mathrm{MF}_{\mathrm{Y}, \mathrm{Z}}, 1 \mathrm{MTP}_{\mathrm{Y}, \mathrm{Z}}, 3 \mathrm{MTP} \mathrm{P}_{\mathrm{X}}$ & .964 & 13 \\
\hline & Full model & .972 & 11 \\
\hline \multirow{3}{*}{$2.2 \mathrm{~Hz}$ mediolateral (left) } & $1 \mathrm{MTP}_{\mathrm{z}}$ and $3 \mathrm{MTP}_{\mathrm{x}}$ & .914 & 9 \\
\hline & $1 \mathrm{MTP}_{\mathrm{Z}}, 3 \mathrm{MTP}_{\mathrm{X}, \mathrm{z}}, 5 \mathrm{MTP}_{\mathrm{z}}$ & .920 & 8 \\
\hline & Full model & .928 & 8 \\
\hline \multirow{3}{*}{$2.2 \mathrm{~Hz}$ mediolateral (right) } & $1 \mathrm{MTP}_{\mathrm{X}, \mathrm{Y}, \mathrm{Z}}, \mathrm{MF}_{\mathrm{X}, \mathrm{Z}}$ & .964 & 4 \\
\hline & $1 \mathrm{MTP}_{\mathrm{X}, \mathrm{Y}, \mathrm{Z},} \mathrm{MF}_{\mathrm{X}, \mathrm{Z}}, \mathrm{GR}_{\mathrm{X}}$ & .965 & 4 \\
\hline & Full model & .968 & 4 \\
\hline \multirow{3}{*}{$2.2 \mathrm{~Hz}$ (anteroposterior) } & $\mathrm{MF}_{\mathrm{Y}}, 1 \mathrm{MTP}$ & .960 & 11 \\
\hline & $\mathrm{MF}_{\mathrm{Y}}, 1 \mathrm{MTP}_{\mathrm{Y}}, 5 \mathrm{MTP}_{\mathrm{Z}}$ & .964 & 10 \\
\hline & Full model & .973 & 9 \\
\hline \multirow{3}{*}{ 3.0 Hz mediolateral (left) } & $1 \mathrm{MTP}_{\mathrm{z}}$ and $3 \mathrm{MTP}_{\mathrm{x}}$ & .976 & 4 \\
\hline & $1 \mathrm{MTP}_{\mathrm{Z}}, 3 \mathrm{MTP}_{\mathrm{X}}, 5 \mathrm{MTP}_{\mathrm{Z}}$ & .985 & 3 \\
\hline & Full model & .987 & 3 \\
\hline \multirow{3}{*}{ 3.0 Hz mediolateral (right) } & $1 \mathrm{MTP}_{\mathrm{x}}, \mathrm{GR}_{\mathrm{x}}$ & .988 & 5 \\
\hline & $1 \mathrm{MTP}_{\mathrm{x}}, 3 \mathrm{MTP}_{\mathrm{x}}, \mathrm{GR}_{\mathrm{x}}$ & .991 & 4 \\
\hline & Full model & .996 & 3 \\
\hline
\end{tabular}




\begin{tabular}{|c|c|c|c|}
\hline \multirow{3}{*}{$3.0 \mathrm{~Hz}$ (anteroposterior) } & $\mathrm{MFY}_{\mathrm{Y}}$ and $3 \mathrm{MTP}_{\mathrm{Y}}$ & .977 & 9 \\
\hline & $\mathrm{MF}_{\mathrm{Y}}, 3 \mathrm{MTP}_{\mathrm{Y}}, 5 \mathrm{MTP} \mathrm{P}_{\mathrm{Y}}$ & .978 & 9 \\
\hline & Full model & .986 & 7 \\
\hline \multirow{3}{*}{ Self-selected mediolateral } & $3 \mathrm{MTP}_{\mathrm{x}}, \mathrm{GR}_{\mathrm{x}}$ & .977 & 8 \\
\hline & $3 \mathrm{MTP}_{\mathrm{x}}, \mathrm{GR}_{\mathrm{x}, \mathrm{z},}, \mathrm{MTP}_{\mathrm{z}}$ & .980 & 7 \\
\hline & Full model & .983 & 7 \\
\hline \multirow{3}{*}{ Self-selected mediolateral } & $1 \mathrm{MTP}_{\mathrm{x}}, 5 \mathrm{MTP}_{\mathrm{x}, \mathrm{Z}}$ & .971 & 5 \\
\hline & $1 \mathrm{MTP}_{\mathrm{X}}, 5 \mathrm{MTP}_{\mathrm{X}, \mathrm{Y}, \mathrm{Z}}, 3 \mathrm{MTP} \mathrm{P}_{\mathrm{X}}$ & .977 & 4 \\
\hline & Full model & .985 & 3 \\
\hline \multirow{3}{*}{$\begin{array}{c}\text { Self-selected } \\
\text { (anteroposterior) }\end{array}$} & $\mathrm{MF}_{\mathrm{Y}, \mathrm{Z},} \mathrm{GR}_{\mathrm{Y}}$ & .963 & 11 \\
\hline & $1 \mathrm{MTP}_{\mathrm{Z}}, \mathrm{MF}_{\mathrm{Y}, \mathrm{Z}}, \mathrm{GR}_{\mathrm{Y}}$ & .965 & 11 \\
\hline & Full model & .972 & 10 \\
\hline
\end{tabular}


Table 4. Forced entry regression: equations derived for each frequency in each direction with $R$, $R^{2}$, standard error of the estimate (SEE) and cross-validation results. Equation is based on marker kinematic input in metres, SEE and cross-validation results are presented in millimetres for clarity.

\begin{tabular}{|c|c|c|c|c|c|c|c|c|c|c|}
\hline $\begin{array}{c}\text { Frequency and } \\
\text { direction }\end{array}$ & Equation & $\mathrm{R}$ & $\mathrm{R}^{2}$ & $\begin{array}{c}\text { Adjuste } \\
\mathrm{d} \mathrm{R}^{2}\end{array}$ & $\begin{array}{l}\text { SEE } \\
\text { (mm }\end{array}$ & $\begin{array}{l}\text { Cross- } \\
\text { validated } \\
\text { RMSD } \\
\text { (mm) }\end{array}$ & $\begin{array}{l}\text { RMSD for } \\
\text { all } \\
\text { subjects } \\
\text { (mm) }\end{array}$ & $\begin{array}{l}\text { Average } \\
\text { differenc } \\
\text { e } \\
(\mathrm{mm})\end{array}$ & $\begin{array}{l}\text { Standard } \\
\text { deviation } \\
\text { (mm) }\end{array}$ & $\begin{array}{l}95 \% \\
\text { confidence } \\
\text { interval } \\
(\mathrm{mm})\end{array}$ \\
\hline $\begin{array}{l}\text { Quiet standing } \\
\text { (left) }\end{array}$ & $\begin{array}{l}\mathrm{CoP}_{\mathrm{x}}=0.059+0.138(1 \mathrm{MTP})+0.186\left(1 \mathrm{MTP}_{\mathrm{Z}}\right)- \\
1.430\left(5 \mathrm{MTP}_{\mathrm{Z}}\right)+0.681\left(\mathrm{MF}_{\mathrm{X}}\right)+.090\left(\mathrm{MF}_{\mathrm{Y}}\right)- \\
0.233\left(\mathrm{MF}_{\mathrm{Z}}\right)\end{array}$ & $\begin{array}{c}1.00 \\
0\end{array}$ & .999 & .999 & 1 & 6 & 3 & 1 & 2 & 4 \\
\hline $\begin{array}{l}\text { Quiet standing } \\
\text { (right) }\end{array}$ & $\begin{array}{l}\mathrm{CoP}_{\mathrm{X}}=0.390+0.476(1 \mathrm{MTP})+0.952\left(1 \mathrm{MTP}_{\mathrm{Y}}\right)+ \\
0.200\left(1 \mathrm{MTP}_{\mathrm{Z}}\right)-0.799(5 \mathrm{MTP})-0.889\left(5 \mathrm{MTP}_{\mathrm{Z}}\right)- \\
0.114\left(\mathrm{MF}_{\mathrm{X}}\right)-1.190\left(\mathrm{MF}_{\mathrm{Z}}\right)\end{array}$ & .999 & .998 & .998 & 1 & 4 & 2 & 1 & 2 & 4 \\
\hline $\begin{array}{l}\text { Quiet standing } \\
\text { (anteroposterio } \\
\text { r) }\end{array}$ & $\begin{array}{l}\mathrm{CoP}_{Y}=-0.237-0.203(1 \mathrm{MTP})+1.739\left(1 \mathrm{MTP}_{Y}\right)+ \\
0.591\left(1 \mathrm{MTP}_{Z}\right)-0.392(5 \mathrm{MTP})+1.139\left(5 \mathrm{MTP}_{\mathrm{Y}}\right)+ \\
3.848\left(5 \mathrm{MTP}_{\mathrm{Z}}\right)+0.785\left(\mathrm{MF}_{\mathrm{X}}\right)-1.707\left(\mathrm{MF}_{\mathrm{Y}}\right)- \\
2.059\left(\mathrm{MF}_{\mathrm{Z}}\right)\end{array}$ & .993 & .987 & .987 & 3 & 12 & 9 & -1 & 9 & 18 \\
\hline
\end{tabular}




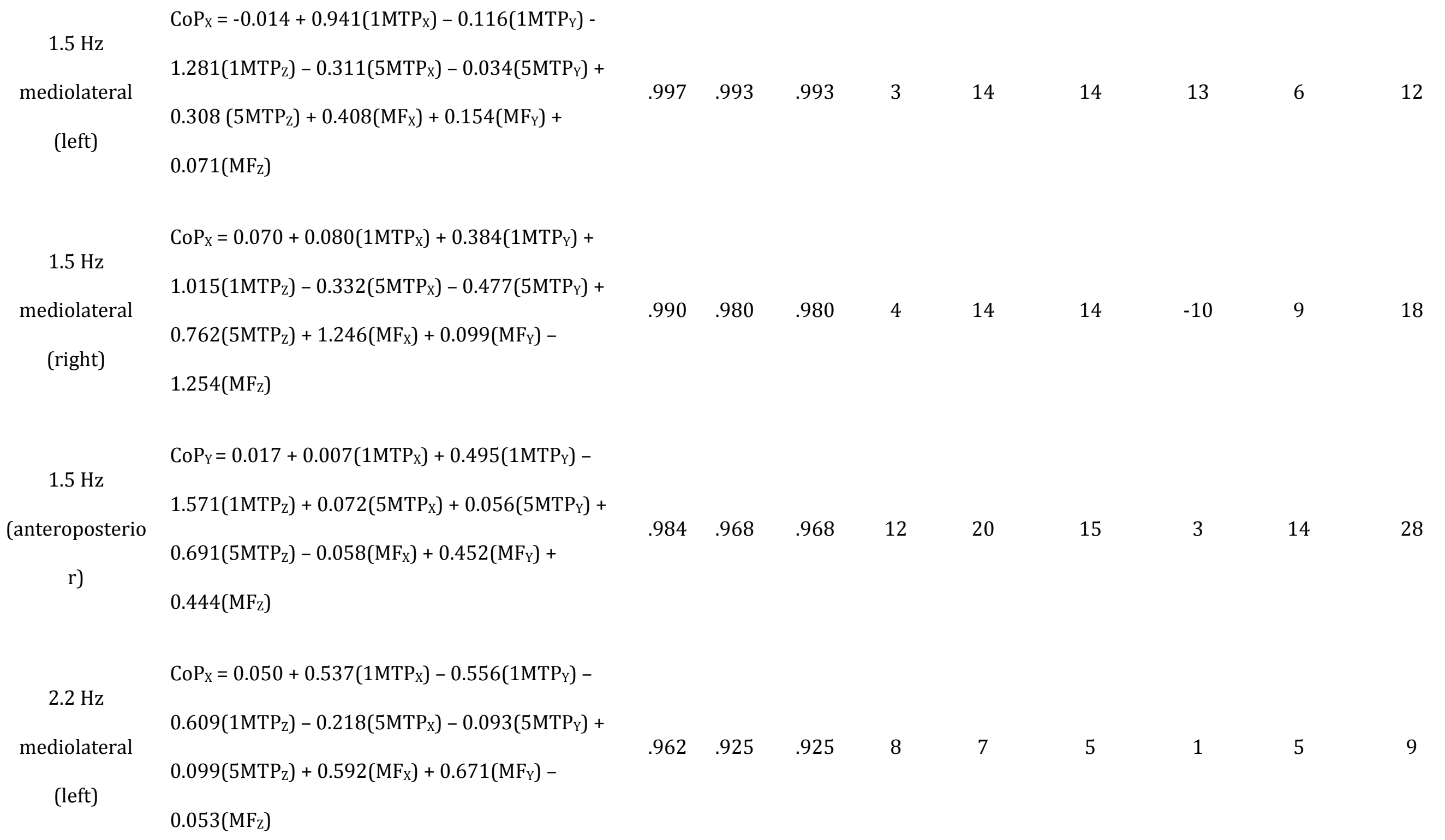


$2.2 \mathrm{~Hz}$

mediolateral

(right)

$2.2 \mathrm{~Hz}$

(anteroposterio

r)

$0.184\left(\mathrm{MF}_{\mathrm{Z}}\right)$

$3.0 \mathrm{~Hz}$

mediolateral

(left)

$0.859\left(1 \mathrm{MTP}_{\mathrm{Z}}\right)-0.205\left(5 \mathrm{MTP}_{\mathrm{X}}\right)+0.216\left(5 \mathrm{MTP}_{\mathrm{Y}}\right)+$ $0.356\left(5 \mathrm{MTP}_{\mathrm{Z}}\right)+0.643\left(\mathrm{MF}_{\mathrm{X}}\right)+0.215\left(\mathrm{MF}_{\mathrm{Y}}\right)+$

$0.243\left(\mathrm{MF}_{\mathrm{Z}}\right)$

$3.0 \mathrm{~Hz}$

$\mathrm{CoP}_{\mathrm{X}}=0.024+0.367\left(1 \mathrm{MTP}_{\mathrm{X}}\right)+0.178\left(1 \mathrm{MTP}_{\mathrm{Y}}\right)+$ $0.872\left(1 \mathrm{MTP}_{\mathrm{Z}}\right)-0.311(5 \mathrm{MTP})+0.031(5 \mathrm{MTP})+$ mediolateral $0.343(5 \mathrm{MTP})+0.976\left(\mathrm{MF}_{\mathrm{X}}\right)-0.204\left(\mathrm{MF}_{\mathrm{Y}}\right)-$

(right)

$$
0.681\left(\mathrm{MF}_{\mathrm{Z}}\right)
$$


$3.0 \mathrm{~Hz}$

(anteroposterio

r)

$\mathrm{CoP}_{\mathrm{Y}}=0.091+0.209\left(1 \mathrm{MTP}_{\mathrm{X}}\right)+0.545\left(1 \mathrm{MTP}_{\mathrm{Y}}\right)$ $2.216(1 \mathrm{MTP} z)+0.339(5 \mathrm{MTP})+0.259\left(5 \mathrm{MTP}_{\mathrm{Y}}\right)+$

$0.866(5 \mathrm{MTP})-0.567\left(\mathrm{MF}_{\mathrm{X}}\right)+0.227\left(\mathrm{MF}_{\mathrm{Y}}\right)-$

$0.110\left(\mathrm{MF}_{\mathrm{Z}}\right)$

Self-selected

$\operatorname{CoP}_{\mathrm{X}}=0.025+0.617\left(1 \mathrm{MTP}_{\mathrm{X}}\right)-0.319\left(1 \mathrm{MTP}_{\mathrm{Y}}\right)-$ $0.994\left(1 \mathrm{MTP}_{\mathrm{z}}\right)-0.202(5 \mathrm{MTP})+0.258\left(5 \mathrm{MTP}_{\mathrm{Y}}\right)+$ $0.612\left(5 \mathrm{MTP}_{\mathrm{Z}}\right)+0.561\left(\mathrm{MF}_{\mathrm{X}}\right)+0.065\left(\mathrm{MF}_{\mathrm{Y}}\right)-$ $0.042\left(\mathrm{MF}_{\mathrm{Z}}\right)$

$\operatorname{CoP}_{\mathrm{X}}=0.060+0.449\left(1 \mathrm{MTP}_{\mathrm{X}}\right)+0.140\left(1 \mathrm{MTP}_{\mathrm{Y}}\right)+$

Self-selected $0.261\left(1 \mathrm{MTP}_{\mathrm{Z}}\right)-0.326(5 \mathrm{MTP})-0.064\left(5 \mathrm{MTP}_{\mathrm{Y}}\right)+$ $0.354\left(5 \mathrm{MTP}_{\mathrm{Z}}\right)+0.898\left(\mathrm{MF}_{\mathrm{X}}\right)-0.048\left(\mathrm{MF}_{\mathrm{Y}}\right)-$

$0.770\left(\mathrm{MF}_{\mathrm{Z}}\right)$

$\mathrm{CoP}_{\mathrm{Y}}=0.036+0.173(1 \mathrm{MTP})+0.340\left(1 \mathrm{MTP}_{\mathrm{Y}}\right)-$

Self-selected (anteroposterio

$0.594(5 \mathrm{MTP})-0.193\left(\mathrm{MF}_{\mathrm{X}}\right)+0.663\left(\mathrm{MF}_{\mathrm{Y}}\right)+$

r) $0.095\left(\mathrm{MF}_{\mathrm{Z}}\right)$

mediolateral

(right)

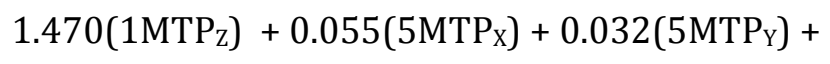


Table 5. Effect of use of marker-based method on sagittal plane ankle moment calculation

\begin{tabular}{|c|c|c|c|c|c|c|c|}
\hline & $\begin{array}{l}\text { Number of hops } \\
\text { analysed }\end{array}$ & $\begin{array}{l}\text { RMSD } \\
\text { (N.m.) }\end{array}$ & $\begin{array}{l}\text { RMSD as } \\
\text { percentage of } \\
\text { maximum } \\
\text { moment (\%) }\end{array}$ & $\begin{array}{l}\text { Absolute difference } \\
\text { in maximum moment } \\
\text { (N.m.) }\end{array}$ & $\begin{array}{l}\text { Percentage } \\
\text { difference in } \\
\text { maximum } \\
\text { moment (\%) }\end{array}$ & $\begin{array}{l}\text { Average } \\
\text { difference in } \\
\text { timing of } \\
\text { maximum } \\
\text { moment (ms) }\end{array}$ & $\begin{array}{c}\text { Absolute } \\
\text { difference in } \\
\text { timing of } \\
\text { maximum } \\
\text { moment (ms) }\end{array}$ \\
\hline $1.5 \mathrm{~Hz}$ & 106 & $8 \pm 6$ & $5.6 \pm 2.9$ & $10 \pm 11$ & $6.6 \pm 6.0$ & $3 \pm 90$ & $36 \pm 83$ \\
\hline $3.0 \mathrm{~Hz}$ & 232 & $6 \pm 4$ & $4.4 \pm 2.3$ & $12 \pm 9$ & $7.9 \pm 5.0$ & $0 \pm 3$ & $1 \pm 3$ \\
\hline SS & 201 & $7 \pm 5$ & $6.0 \pm 4.2$ & $15 \pm 17$ & $11.8 \pm 11.3$ & $0 \pm 16$ & $7 \pm 14$ \\
\hline
\end{tabular}

